\title{
Effect of Paclitaxel-loaded Nanoparticles on the Viability of Human Hepatocellular Carcinoma HepG2 Cells
}

\author{
Zhi-Hong Hou ${ }^{1 \&}$, Wen-Cui Zhao ${ }^{1 \&}$, Qi Zhang ${ }^{1 *}$, Wei Zheng ${ }^{2}$
}

\begin{abstract}
Objective: To explore effects of paclitaxel-loaded poly lactic-co-glycolic acid (PLGA) particles on the viability of human hepatocellular carcinoma (HCC) HepG2 cells. Materials and Methods: The viability of HepG2 cells was assessed using MTT under different concentrations of prepared paclitaxel-loaded particles and paclitaxel $(6.25,12.5,25,50$, and $100 \mathrm{mg} / \mathrm{L})$, and apoptosis was analyzed using Hochest33342/Annexin V-FITC/PI combined with an IN Cell Analyzer 2000. Results: Paxlitaxel-loaded nanoparticles were characterized by narrow particle size distribution $(158.6 \mathrm{~nm}$ average particle size). The survival rate of HepG2 cells exposed to paclitaxel-loaded PLGA particles decreased with the increase of concentration and time period $(P<0.01$ or $P<0.05)$, the dose- and time-dependence indicating sustained release $(P<0.05)$. Moreover, apoptosis of HepG2 cells was induced, again with an obvious dose- and time-effect relationship $(P<0.05)$. Conclusions: Paclitaxel-loaded PLGA particles can inhibit the proliferation and induce the apoptosis of HCC HepG2 cells. This new-type of paclitaxel carrier body is easily made and has low cost, good nanoparticle characterization and sustained release. Hence, paclitaxelloaded PLGA particles deserve to be widely popularized in the clinic.
\end{abstract}

Keywords: Paclitaxel-loaded nanoparticles - HCC - HepG2 cells - viability - apoptosis

Asian Pac J Cancer Prev, 16 (5), 1725-1728

\section{Introduction}

Paclitaxel, a kind of diterpenoid compound and complex secondary metabolite derived from the genus of taxus chinensis, is a broad-spectrum chemotherapeutic drug highly effective against cancer found in the 20th century (Dong et al., 2012; Xu et al., 2012). It is a highly effective tubulin inhibitor, different from the targets and mechanisms of microtubule inhibitors. That is, it can influence the dynamic equilibrium between microtubule polymerization and depolymerization, hinder the formation of spindle fibers and block the cell cycle in phase G2/M by coupling specific loci of cell microtubules, promoting microtubule polymerization, making the microtubule structure stable and blocking the depolymerization into subunits, consequently resulting in cell apoptosis and death (Symmans et al., 2000; Ma et al., 2010).

At present, paclitaxel is clinically used as the firstline treatment for breast cancer, lung cancer, esophageal cancer, colon cancer, lymphoma, acute leukemia, melanin, ovarian cancer and gastric cancer (Pitakkarnkul et al., 2013; Jianmin et al., 2014; Tanaka et al., 2014; Feng et al., 2015; Langer et al., 2015). However, it is hard to be absorbed by taking orally due to its physicochemical property, such as poor water solubility, so it is mostly made into injection. Nevertheless, polyoxyethylene castor oil injection presently used in clinic causes many severe adverse reactions, such as hypersensitivity, toxic renal damage, neurovirulence and cardiotoxicity. To solve this problem, nanocarrier is attracted widespread attention (Chao et al., 2007; Gong et al., 2009). In this study, paclitaxel-loaded poly lactid-co-glycolic acid (PLGA) nanoparticles were prepared, and their inhibitory and apoptotic effects on human hepatocellular carcinoma (HCC) HepG2 cells were observed.

\section{Materials and Methods}

\section{Key reagents and equipments}

Laser particle analyzer was purchased from British Malvern Company. Transmission electron microscopy (TEM) and scanning electron microscope (SEM) were provided by Japanese Hitach Company. Probe-type ultrasonic instrument was purchased from American Sonic and Materials Company, inverted fluorescence microscope from Leica Company, IN Cell Analyzer 2000 from American GE Company, $\mathrm{CO}_{2}$ cell culture box from Heal Force Bio-meditech Holdings Group, paclitaxel API from Wuhan Hezhong Bio-Chemical Manufacture Co., Ltd, DAPI and MTT from Sigma Company and Annexin V-FITC Apoptosis Assays Kit from Beyptime. Both 
dichloromethane and polyvinyl Acetate were provided by Tianjin Damao Chemical Reagent Factory.

\section{Preparation of paclitaxel-loaded PLGA nanoparticles}

Paclitaxel powder (30 mg) and PLGA (100 mg) were weighed and dissolved into dichloromethane solution. After completely dissolved, the solution was injected in $1 \%$ polyethylene aqueous solution, performed with ultrasonic dispersion for 5 min under the condition of ice bath, and then formed oil-in-water emulsion. The solution was stirred for $4 \mathrm{~h}$ in fuming cupboard under the normal pressure until the organic solvent was removed completely, and centrifuged at $23000 \mathrm{r} / \mathrm{min}$ for $20 \mathrm{~min}$. The solidified nanoparticles were collected, washed by distilled water and centrifuged for 3 times. After freeze drying, paclitaxel-loaded PLGA nanoparticles were prepared successfully and preserved at $4^{\circ} \mathrm{C}$.

Surface characterization of paclitaxel-loaded PLGA nanoparticles

The surface characterization was described using laser particle analyzer, TEM and SEM. Particle size determination: A small number of prepared paclitaxelloaded PLGA nanoparticles were dissolved in double distilled water (as solvent) and mixed evenly to make the solution clear, and without coalescence particles. The particle size distribution was detected using particle size instrument. Paclitaxel-loaded nanoparticles observed under SEM: A small number of paclitaxel-loaded nanoparticles were blown by rubber pipette bulb onto double stick tape which was adherent to sample stage and given metal spraying and finally observed under SEM. Paclitaxel-loaded nanoparticles observed under TEM: A small number of paclitaxel-loaded nanoparticles were dispersed evenly into double distilled water, then dripped into 300-mesh copper net and determined after natural drying.

\section{Cell culture}

Human HCC cell line HepG2 was purchased from Cell Resource Center, Shanghai Institutes for Biological Sciences. HepG2 cells were inoculated into RPMI 1640 culture medium which contained $10 \%$ of fetal bovine serum (FBS), $100 \mathrm{U} / \mathrm{mL}$ of penicillin and $100 \mathrm{mg} / \mathrm{L}$ of streptomycin, and then the culture medium was placed in the incubator with $5 \% \mathrm{CO}_{2}$ at $37^{\circ} \mathrm{C}$. Culture solution was exchanged every $1 \sim 2 \mathrm{~d}$. After they grew against the wall, HepG 2 cells were digested by $0.25 \%$ of trypsase for sub-culturation. Cells in logarithmic phase were collected for ensuing experiment.

\section{Cell viability detected by MTT}

HepG2 cells in logarithmic phase were inoculated into 96-well plate by $5 \times 104 /$ well, $100 \mathrm{uL} /$ well. Experimental group and control group were designed, respectively added with paclitaxel-loaded nanoparticles and paclitaxel at different concentrations $(6.25,12.5,25,50$, and 100 $\mathrm{mg} / \mathrm{L}$ ) and cultured for 24, 48 and $72 \mathrm{~h}$. Each well was added with $50 \mu \mathrm{L}$ of MTT solution $(5 \mathrm{~g} / \mathrm{L})$ and continued to incubate for $4 \mathrm{~h}$ at $37{ }^{\circ} \mathrm{C}$. After centrifugation for 5 min, the culture medium was removed and each well was added with $150 \mu \mathrm{L}$ of DMSO particles for shaking until the particles were completely resolved. A microplate reader was used to detect the optical density (OD) at the wavelength of $492 \mathrm{~nm}$ to observe the viability of HepG2 cells. Cell viability $(\%)=(\mathrm{OD}$ of experimental group/OD of control group) $\times 100 \%$. The experiment was repeated 3 times for average one.

\section{Detection of cell apoptosis}

HepG 2 cells in logarithmic phase were incubated in 96well plate in a $5 \% \mathrm{CO}_{2}$ incubator at $37^{\circ} \mathrm{C}$. Each well was $100 \mu \mathrm{L}$, containing $5000 \sim 7000$ cells. Drug toxicity and dose dependence were observed. Paxlitaxel nanoparticles at different concentrations $(12.5,25,50$ and $100 \mathrm{mg} / \mathrm{L})$ were added in experimental group, while $0.1 \%$ DMSO solution in control group. After incubation for 24, 48 and $72 \mathrm{~h}, 30 \mu \mathrm{L}$ of $2.5 \%$ Annexin V-FITC binding buffer was added, shaked slightly and incubated for $10 \mathrm{~min}$ at room temperature away from light. Then the supernatant was removed and $30 \mu \mathrm{L}$ of Annexin V-FITC binding buffer with $5 \%$ propidium iodide was added for ice-bath incubation for 10 min away from light. Afterwards, the supernatant was removed again and cells were washed by PBS twice, added with $50 \mu \mathrm{L}$ of $10 \mathrm{mg} / \mathrm{L}$ Hochest 33342 for incubation for $10 \mathrm{~min}$ away from light and washed by PBS twice at $4{ }^{\circ} \mathrm{C}$. Finally, each well was added with $150 \mu \mathrm{L}$ PBS. Finally, the apoptosis of HepG2 cells was detected using IN Cell Analyzer 2000.

\section{Statistical data analysis}

SPSS13.0 software package was used to analyze the data. Measurement data were compared with $t$ test, expressed as the mean \pm standard deviation $(\mathrm{x} \pm \mathrm{s})$. A value of $P<0.05$ was considered to be statistically significant.

\section{Results}

Surface characterization of paclitaxel-loaded nanoparticles

Paxlitaxel-loaded nanoparticles were characterized by narrow particle size distribution, with the average particle size being $158.6 \mathrm{~nm}$, ranged 78.0 178.8 nm (Figure 1). TEM showed paclitaxel-loaded nanoparticles had smooth surface, uniform particle size and sphere-like shape. SEM analysis showed that paxlitaxel-loaded nanoparticles were like good solid balls, with the particle size being 163.69 $\mathrm{nm}$ and $92.26 \mathrm{~nm}$ respectively (Figure 2 3).

Effect of paclitaxal-loaded nanoparticles and paclitaxal on the viability of HepG2 cells

After intervention for 24,48 and $72 \mathrm{~h}$, the viability

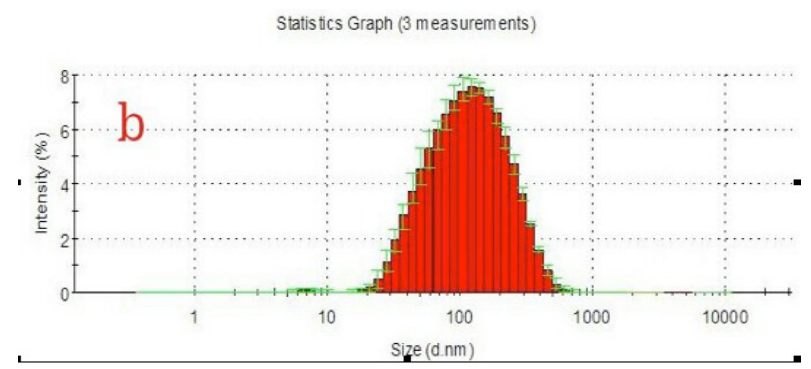

Figure 1. Particle Size Distribution of Paxlitaxel-loaded Nanoparticles 


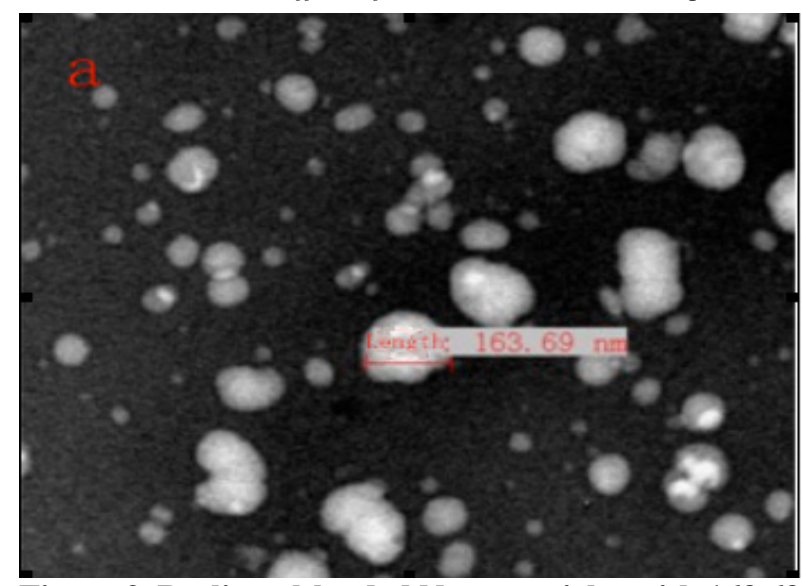

Figure 2. Paclitaxel-loaded Nanoparticles with 163.69 nm of Particle Size

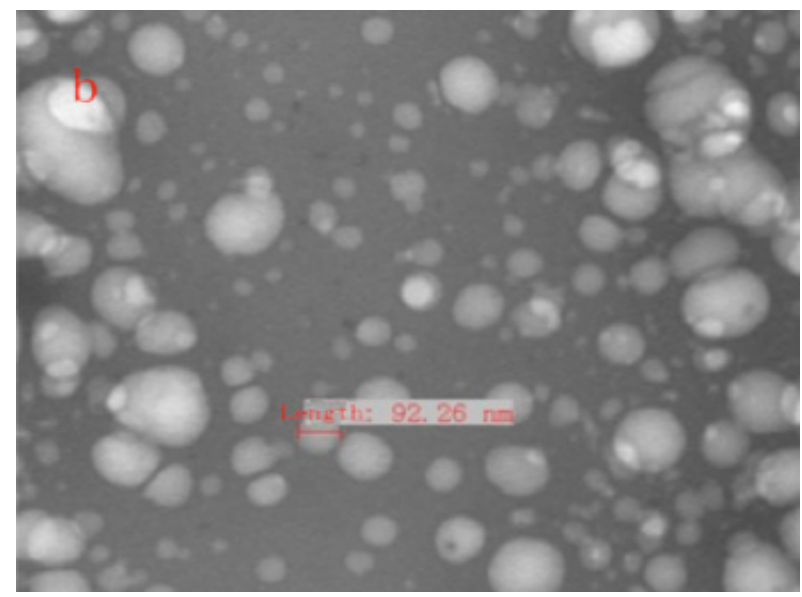

Figure 3. Paclitaxel-loaded Nanoparticles with 92.26 nm of Particle Size

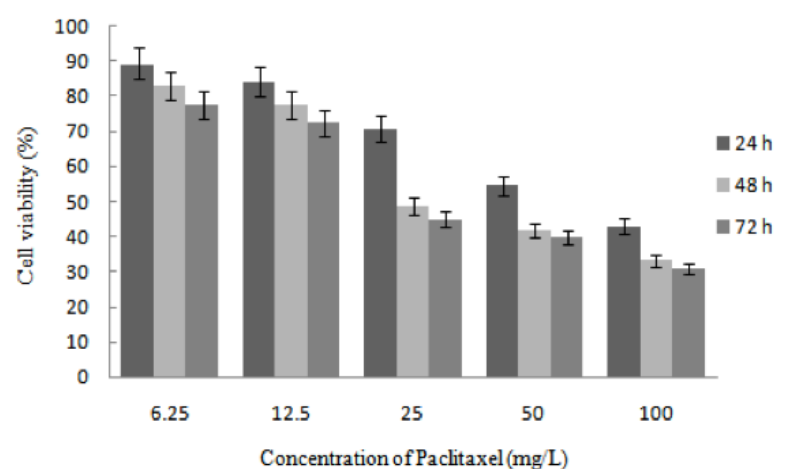

Figure 4. Effect of Paclitaxal on the Viability of HepG2 Cells

and growth condition of HepG2 cells under different concentrations of paclitaxel-loaded PLGA particles and paclitaxel were respectively observed. The survival rate of HepG 2 cells intervened by paclitaxel decreased with the increase of concentration $(P<0.05)$, but tended to be stable after intervention for $48 \mathrm{~h}$, showing that paclitaxel could inhibit the viability of HepG2 cells and the inhibitory effect increased as the concentration of paclitaxel increased, but nearly reached the peak after intervention for $48 \mathrm{~h}$ (Figure 4). However, the survival rate of HepG2 cells intervened by paclitaxel-loaded PLGA particles decreased with the increase of concentration and time extension $(P<0.01$ or $P<0.05)$, showing that paclitaxel-loaded PLGA particles suppressed the viability of HepG2, which was in a dose-

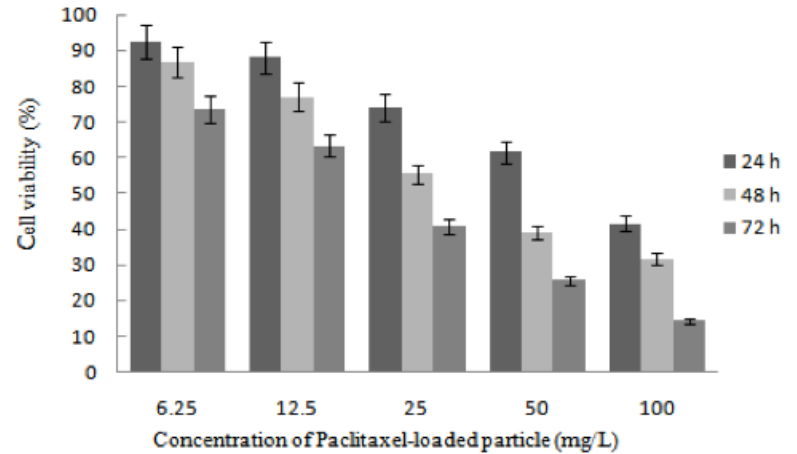

Figure 5. Effect of Paclitaxal-loaded Nanoparticles on the Viability of HepG2 Cells

Table 1. Apoptosis Rates of HepG2 Cells Intervened by Different Concentrations of Paclitaxel-loaded PLGA Particles at Different Time Points $(\mathrm{x} \pm \mathrm{s}, \%)$

\begin{tabular}{|c|c|c|c|c|}
\hline \multicolumn{2}{|l|}{ Groups } & Culturetim & \multicolumn{2}{|c|}{$\begin{array}{l}\text { ne Cell Necrosis/late } \\
\text { apoptosis rate apoptosis rate }\end{array}$} \\
\hline Control group & & & $2.7 \pm 9.8$ & $0.2 \pm 0.8$ \\
\hline \multirow{12}{*}{$\begin{array}{l}\text { Experimental } \\
\text { group }\end{array}$} & $12.5 \mathrm{mg} / \mathrm{L}$ & $24 \mathrm{~h}$ & $9.6 \pm 3.4 *$ & $4.6 \pm 0.8 * *$ \\
\hline & & $48 \mathrm{~h}$ & $16.3 \pm 6.1^{* *}$ & $5.0 \pm 1.9 * *$ \\
\hline & & $72 \mathrm{~h}$ & $28.8 \pm 4.6 * *$ & $8.4 \pm 2.1 * *$ \\
\hline & $25 \mathrm{mg} / \mathrm{L}$ & $24 \mathrm{~h}$ & $14.5 \pm 3.1 * *$ & $5.6 \pm 2.7 * *$ \\
\hline & & $48 \mathrm{~h}$ & $23.4 \pm 5.8 * *$ & $8.4 \pm 3.3 * *$ \\
\hline & & $72 \mathrm{~h}$ & $59.1 \pm 8.2 * *$ & $14.6 \pm 2.8 * *$ \\
\hline & $50 \mathrm{mg} / \mathrm{L}$ & $24 \mathrm{~h}$ & $18.6 \pm 8.8^{* *}$ & $8.4 \pm 2.5 * *$ \\
\hline & & $48 \mathrm{~h}$ & $44.7 \pm 7.3 * *$ & $13.1 \pm 3.2 * *$ \\
\hline & & $72 \mathrm{~h}$ & $60.7 \pm 7.0 * *$ & $26.8 \pm 6.6 * *$ \\
\hline & $100 \mathrm{mg} / \mathrm{L}$ & $24 \mathrm{~h}$ & $25.9 \pm 9.3 * *$ & $10.0 \pm 4.2 * *$ \\
\hline & & $48 \mathrm{~h}$ & $43.8 \pm 6.5^{* *}$ & $19.4 \pm 3.7 * *$ \\
\hline & & $72 \mathrm{~h}$ & $61.6 \pm 7.8 * *$ & $31.5 \pm 4.4 * *$ \\
\hline
\end{tabular}

Compared with control group, $* P<0.05$, $* * P<0.01$

and time-dependence manner. Besides, it also indicated obviously sustained release (Figure 5).

Effect of paclitaxal-loaded nanoparticles on the apoptosis of HepG2 cells

The apoptosis rate of human HCC HepG2 cells intervened by paclitaxel-loaded PLGA particles was analyzed using Hochenst33342/Annexin V-FITC/PI combined with IN Cell Analyzer 2000. Paclitaxel-loaded PLGA particles could induce the apoptosis of HepG2 cells obviously, which was in an obvious dose- and time-effect relationship $(P<0.05$ or $P<0.01)$ (Table 1$)$.

\section{Discussion}

Many anti-tumor drugs do not work efficiently in treating neoplastic disorders duo to the solubility, stability, metabolism and toxicity to some extent (Qiu et al., 2009; Wang et al., 2013). Paclitaxel is an alkaloid with unique anti-tumor mechanism, effective in multiple advanced tumors and such effects have been proved. At present, many preparations of paclitaxel are mainly based on lipidosomes (Xu et al., 2013). Although lipidosome is as a drug carrier with many advantages, the molecule of natural-phospholipid lipidosome contains unsaturated fatty acid chains which are susceptible to oxidization and hydrolysis, and results in the toxicity caused by 
drug leakage, which limits the application of paclitaxel (Danhier et al.,2015). To solve this issue, selection of drug carriers have been attracted widespread attention (Desai et al., 2013). PLGA nonoparticles were applied in this study, and the results showed that PLGA nonoparticles could extend the time of drug effect and release drugs slowly, with high stability in vitro and small toxicity, suggesting that it is an ideal fat soluble drug carrier. Paclitaxel-loaded PLGA particles were prepared easily, with low cost and energy consumption. In this study, paxlitaxel-loaded nanoparticles were characterized by narrow particle size distribution, with the average particle size being 158.6 $\mathrm{nm}$, ranged 78.0 178.8 nm. TEM showed paclitaxelloaded nanoparticles had smooth surface, uniform particle size and sphere-like shape. SEM analysis showed that paxlitaxel-loaded nanoparticles were like good solid balls.

Multiple studies showed that many chemotherapeutics could inhibit the proliferation and induce cell apoptosis, such as paclitaxel (Yadav et al., 2014; Lim et al., 2015; Lin et al., 2015). By promoting microtubulin to form into canaliculus and suppressing depolymerization, paclitaxel-loaded drugs can lead to aberrant arrangement of microtubule fasolculus, formation of asteriform, abnormal function of spindle apparatus and inhibition of cell mitosis, thus inducing apoptosis and inhibiting cell proliferation (Pan et al., 2013). MTT assay showed that the survival rate of HepG2 cells intervened by paclitaxel decreased with the increase of paclitaxel concentration, but tended to be stable after intervened for $48 \mathrm{~h}$, showing that paclitaxel could inhibit the viability of HepG2 cells and the inhibitory effect increased as the concentration of paclitaxel increased, but nearly reached the peak after intervention for $48 \mathrm{~h}$. However, the survival rate of HepG2 cells intervened by paclitaxel-loaded PLGA particles decreased with the increase of concentration and time extension, showing that the inhibitory effect of paclitaxelloaded PLGA particles on the viability of HepG2 cells was in a dose- and time-dependence manner and had obviously sustained release.

In conclusion, paclitaxel-loaded PLGA particles can inhibit the proliferation and induce the apoptosis of HCC HepG2 cells. It is a new-type paclitaxel carrier body which is easily to be made and has low cost, good nonoparticle characterization and sustained release. Hence, paclitaxelloaded PLGA particles deserve to be widely popularized in clinic.

\section{References}

Chao G, Fan L, Jia W, et al (2007). Synthesis, characterization and hydrolytic degradation of degrable poly (butylenes terephthalate)/poly (ethlene glycol) (PBT/PEG) copolymers. J Mater Sci Mater Med, 18, 449-55.

Danhier F, Danhier P, De Saedeleer CJ, et al (2015). Paclitaxelloaded micelles enhance transvascular permeability and retention of nanomedicines in tumors. Int J Pharm, 479, 399-407.

Desai N (2007). Nanoparticle albumin bound (nab) technology: targeting tumors through the endothelial gp60 receptor and SPAR. Nanomed Nanotechnol Biol Med, 3, 339.

Dong XL, Xu PF, Miao C, et al (2012). Hypoxia decreased chemosensitivity of breast cancer cell line MCF-7 to paclitaxel through cyclin B1. Biomed Pharmacother, 66,
$70-5$.

Feng W, Xiaoyan X, Xuan Y, et al (2015). Silencing stathminmodulating efficiency of chemotherapy for esophageal squamous cell cancer with paclitaxel. Cancer Gene Ther, [Epub ahead of print].

Gong C, Shi S, Wu L, et al (2009). Biodegradable in situ gel-forming controlled drug delivery system based on thermosensitive PCL-PEG-PCL hydrogel. Part 2: sol-gelsol transition and drug delivery behavior. Acta Biomater, $\mathbf{5}, 3358-70$.

Jianmin Zou, Gundry S, Ganic E, et al (2014). Mathematical models for absorption and efficacy of ovarian cancer treatments. Conf Proc IEEE Eng Med Biol Soc, 3442-5.

Langer CJ, Hirsh V, Ko A, et al (2015). Weekly nab-paclitaxel in combination with carboplatin as first-line therapy in patients with advanced non-small-cell lung cancer: analysis of safety and efficacy in patients with renal impairment. Clin Lung Cancer, 16, 112-20.

Lim SJ, Choi HG, Jeon CK, et al (2015). Increased chemoresistance to paclitaxel in the MCF10AT series of human breast epithelial cancer cells. Oncol Rep, 33, 2023-30.

Lin Y, Jiang D, Li Y, et al (2015). Effect of sun ginseng potentiation on epirubicin and paclitaxel-induced apoptosis in human cervical cancer cells. J Ginseng Res, 39, 22-8.

Ma GL, Miao BL, Song CX (2010). Thermosensitive PCL-PEGPCL hydrogels: Synthesis, characterization, and delivery of proteins. J Appl Polym Sci, 116, 1985-93.

Qiu D, Zhu H (2009). Advances in research on surface modification of paclitaxel-polylactide nanoparticles. Chem Ind Eng Prog, 28, 1198-201.

Pan Y, Ni HH, Zou AF et al (2013). The research of paclitaxelloaded nanoparticles by human serum albumin as drug delivery vectors. Chin J Antibiot, 28, 853-8.

Pitakkarnkul S, Tangjitgamol S, Srijaipracharoen S, et al (2013). Treatment outcomes of paclitaxel for refractory or recurrent epithelial ovarian cancer patients in Thailand. Asian Pac J Cancer Prev, 14, 2421-7.

Symmans WF, Volm MD, Shapiro RL, et al (2000). Paclitaxelinduced apoptosis and mitotic arrest assessed by serial fine-needle aspiration: implications for early prediction of breast cancer response to neoadjuvant treatment. Clin Cancer Res, 6, 4610-7.

Tanaka S, Iwamoto M, Kimura K, et al (2014). Phase II study of neoadjuvant anthracycline-based regimens combined with nanoparticle albumin-bound paclitaxel and trastuzumab for human epidermal growth factor receptor 2-positive operable breast cancer. Clin Breast Cancer, [Epub ahead of print].

Xu M, Takanashi M, Oikawa K, et al (2012). Identification of a novel role of Septin 10 in paclitaxel-resistance in cancers through a functional genomics screen. Cancer Sci, 103, 821-7.

Xu X, Wang L, Xu HQ, et al (2013). Clinical comparison between paclitaxel liposome (Lipusu $®$ ) and paclitaxel for treatment of patients with metastatic gastric cancer. Asian Pac J Cancer Prev, 14, 2591-4.

Wang H, Xu LF, Zhang C, et al (2013). Paclitaxel-loaded PLGA/ f69 nanoparticles reverse multidrug resistance in breast cancer cells. Bme and Clin Med, 17, 17-21.

Yadav D, Anwar MF, Garg V, et al (2014). Development of polymeric nanopaclitaxel and comparison with free paclitaxel for effects on cell proliferation of MCF-7 and B16F0 carcinoma cells. Asian Pac J Cancer Prev, 15, 2335-40. 